\title{
Simulation of Eddy Current Separation of Gold Particles from Sands
}

\author{
Ayad Ahmed Nour El Islam ${ }^{a^{*}}$, Ayad Abdelghani $^{\mathrm{b}}$, Ramdani Youcef ${ }^{\mathrm{c}}$ \\ ${ }^{a}$ djilali Liabes University IRECOM Laboratory and Kasdi merbah University, ouargla 30000 , Algeria \\ ${ }^{b}$ djilali liabesUniversity, ICEPS Laboratory Sidi Bel Abbes 22000, Algeria \\ ${ }^{c}$ djilali liabesUniversity IRECOM Laboratory Sidi Bel Abbes 22000, Algeria
}

\begin{abstract}
The particles of gold can be reuse and recovered from electronics products and cards by sorting from many other metals or from sands. In mixtures of small gold spheres and sands have been sorted by an efficient method called eddy current separation able to separate the gold from a mixture of non ferrous particles. It's a mining sort and recycling industry. This study is based on the ejected force created by the eddy currents induced and the rotation of drum. These eddy currents create a opposing magnetic field to create magnetodynamic repulsive force between permanent magnet of separator and gold particles, these last will be ejected in collector by gravity force.
\end{abstract}

Index Terms: Eddy-current separator, nonferrous metals, wastes, recycle, magnetic force.

(C) 2016 Published by MECS Publisher. Selection and/or peer review under responsibility of the Research Association of Modern Education and Computer Science.

\section{Introduction}

Eddy current separation is an effective way of recovering nonferrous metals (aluminum and copper) from streams of industrial or municipal waste, by inducing eddy currents inside the conductive particles. These currents generate a magnetic moment in the particles which are then sorted by the gradient field of the permanents magnets P. C. Rem et al, 1998, Fabiano M and al, 2004. The conductive particles (Gold Au) are accelerated so as to follow the motion of the drum and will be ejected far from the separator. Poorly conducting or non conductive materials (sands), will drop near to the drum. The trajectory of conductive particles depends on combination of the magnetic force, gravity, friction and the air forces (Figure 1).

Eddy current separator already realized by many experimentally works of research and industrial application, Shunli Zhang et al., 1998 and Jujun Ruan et al., 2011, R. Ko“hnlechner et al., 2002, R. Meier-Staude et al., 2002, Shunli Z et al, 1999.

Eddy current separation is effective method for sorting any nonferrous metal as well as in several other waste types. Edison (1847-1931), who wanted technique of eddy current separation to separate gold from beach sands in California,

\footnotetext{
* Corresponding author. Tel.: 213661244622; fax: 213591452

E-mail address: ayadnourislam@yahoo.frayad_abdelghani@yahoo.fr ramdaniy@yahoo.fr
} 
patented the first practical application of eddy current separation technology it is impossible to move these gold particles smaller than $0.1 \mathrm{~mm}$ with eddy current phenomena. The eddy current separators used magnetic fields of single coils, electromagnet or linear motor technology, or on permanent rare earth magnets Engineering company a division of arrowhead inductrial corporation USA.

In the study eddy-current separator is composed by number pairs of permanent magnet oriented alternately $\mathrm{N}-\mathrm{S}$ and S-N respectively, will be simulate in 2D by COMSOL Multiphysics with finite element method to represent magnetic propriety of separator, the variable field of the rotating drum induces eddy currents in electrically conductive particles of gold. These last particles (gold) will be repulsed by deflection magnetic force.

These magnetic proprieties will be computed as function of magnetic parameters of separator, particles and operational parameters of separation. The results of study will show the effects of these parameters on the Lorentz magnetic force and the eddy-current induced in the particles of gold.
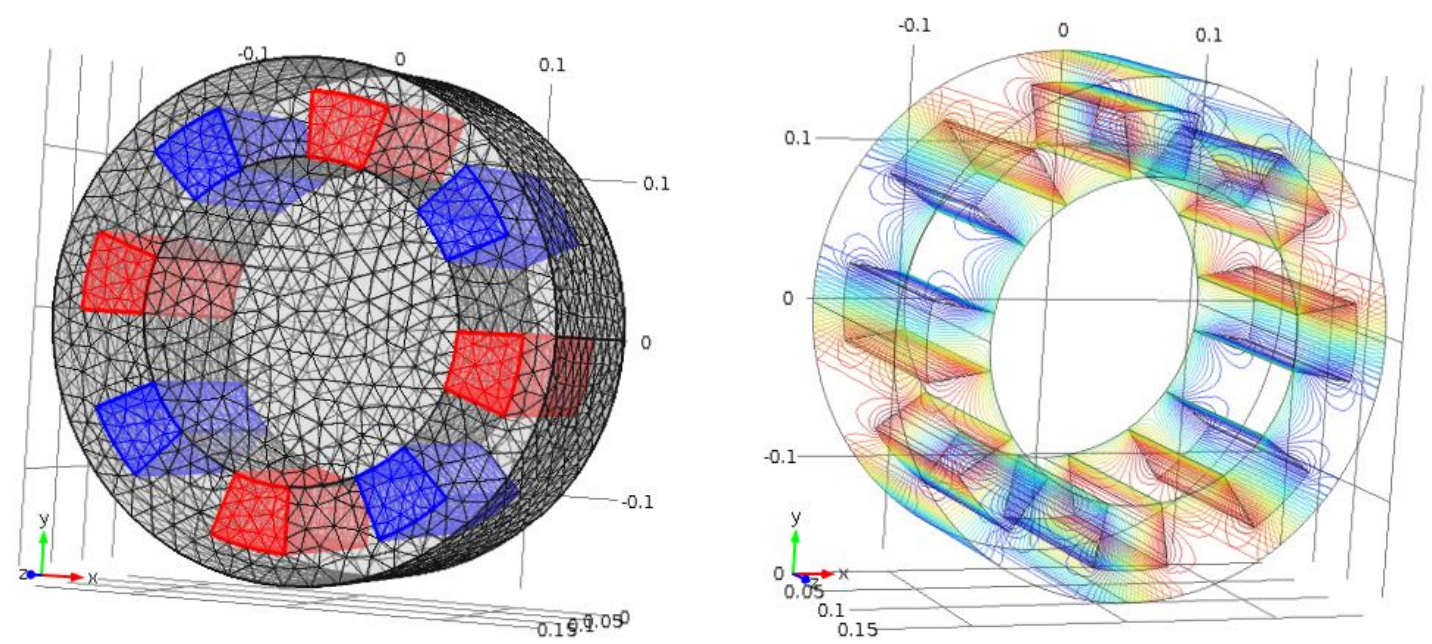

Fig.1. Eddy Current Separator Drum in 3D

\section{Repulsive Magnetic Force}

When the nonferrous particles are positioned in fluctuant magnetic field, the induced potential $\mathrm{V}$ by Faraday's Law states that when a conducting particle intersects an alternating magnetic field, an electrical current is induced on the skin of the particle, Popovic, Branko D 1971, Mihai L et al,2005, The induced emf is describes by:

$$
\vec{e}=-\frac{\partial \phi}{d t}=\vec{V}
$$

This equation gives the induced emf in terms of the rate of change of flux at any instant of time. As aluminium particle moving near to the rotating magnetic drum in ECS, the relative linear velocity between the flake and magnet can be expressed as:

$$
v^{\prime}=v-\omega m R
$$

R: Radius of drum (m). The suffered variation of magnetic flux of the particle can be given as: 


$$
\nabla \phi=\iint B d S
$$

The applied alternating magnetic flux is supposed to cross the particle since the big gaps of size and speed between the flake and the magnetic drum Shunli $\mathrm{Z}$ et al ,1999. As w>>v0

$$
\vec{V}=-A\left[\omega-v_{0}\right] \frac{\partial B}{\partial \varphi} \approx-A \omega \frac{\partial B}{\partial \varphi}
$$

A: square of particle, $w$ is the angle velocity of drum, $\mathrm{v}_{0}$ velocity of feed belt. Induced current in metallic's particles is calculated as:

$$
I=\frac{V}{R}=-\frac{m}{2 \pi} \frac{\sigma}{\rho} \omega \frac{\partial B}{\partial \varphi}
$$

Where, $\mathrm{m}$ is the mass, $\sigma$ is the conductivity, $\rho$ is the density $\mathrm{R}$ resistance, Huifen Zhang1, et al., 2014, $\mathrm{Z}$. Schlett and al ,2002. Therefore, the induced magnetic force upon nonferrous particle is written as:

$$
F=M_{\rho} \frac{\partial B_{\rho}}{\partial \rho}+M_{\varphi} \frac{\partial B_{\rho}}{\partial \varphi}=-\frac{1}{8} m D^{2} \frac{\sigma}{\rho} \omega\left(\frac{\partial B_{\rho}}{\partial \rho} \frac{\partial B_{\rho}}{\partial \varphi}\right)
$$

Magnetic force exerted on a nonferrous particle in eddy current separator of alternative magnetic field related to many parameters for example: induced eddy-current, rotation speed of drum, magnetic gradient of permanent magnet, the conductivity and density of the non ferrous particles, the total magnetic force may be written as:

$$
F=\delta \frac{\sigma}{\rho} \omega(\nabla B)^{2}
$$

With is the constant (depend on metal and magnetic field), Huifen Zhang1 et al., 2014.

\section{Simulations Results}

Variation of magnetic induction surface $B$ from 0.12 to $0.84 \mathrm{~T}$ of permanent magnet $\mathrm{P}=4$, with air-gap e=2cm (figure 


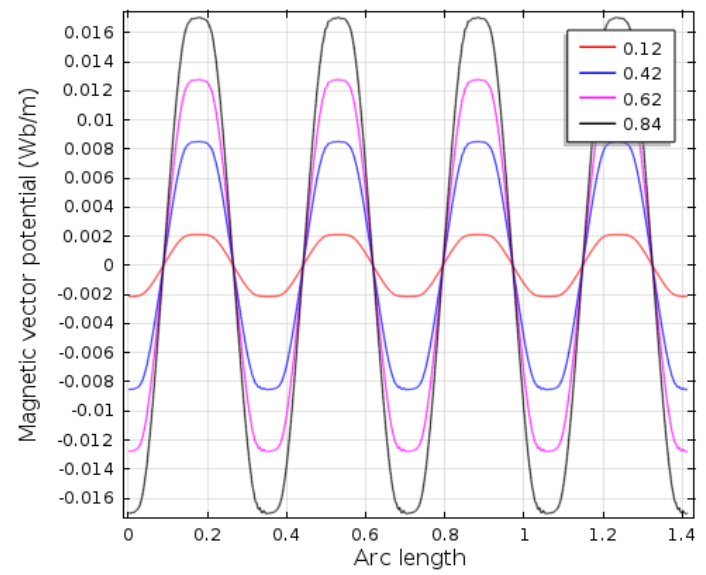

Fig.2. Measurement of Magnetic Vector Potential Around the Drum

\subsection{Variation of alternative magnetic field}

The Effect of variation of alternative magnetic field of eddy current separator is assured by change the magnetization of each permanent magnet from 0.12 to $0.84 \mathrm{~T}$. Figure 3 represent the measurement of magnetic vector potential produced near the drum of separator (in the active zone of the field) where non-ferrous particles pass in the process of separation, when the magnetization of permanent magnet increase the magnetic characteristics increase (alternative magnetic field, magnetic vector potential) and we will have very important separation with big rate and purity and separation performance will be improved, J. Svoboda et al 2003, Jujun $\mathrm{R}$, et al 2011.

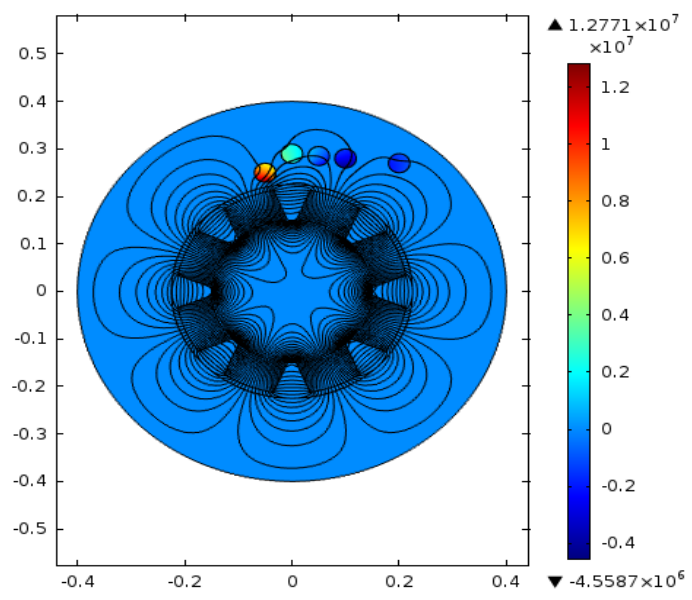

Fig.3. Induced eddy-current in Rejected Non Ferrous Particles $\left[\mathrm{A} / \mathrm{m}^{2}\right]$

\subsection{Induced eddy current in particle}

The induced eddy current in removal fine gold particle is represented in fig. 3 with big density, eddy currents will arise in the particle, generating a magnetic field that opposes the field applied. 


\subsection{Variation of remanent flux density and computation of magnetic force}

We change the remanent flux density of permanent magnet from 0.12 to $1 \mathrm{~T}$ and we record the maximum values of induced eddy current and deflection magnetic force of circle gold particle with angular speed of rotation drum $300 \mathrm{Rpm}$ (table 1).

Table 1. Variation of Remanent Flux Density of Permanent Magnet

\begin{tabular}{ccc}
\hline Remanent flux density [T] & Induced eddy current $\left(\mathrm{A} / \mathrm{mm}^{2}\right)$ & Magnetic force $(\mathrm{mN})$ \\
\hline 0.12 & 0.25 & 0.07 \\
0.22 & 0.45 & 0.24 \\
0.32 & 0.65 & 0.5 \\
0.42 & 0.82 & 0.88 \\
0.52 & 1.1 & 1.3 \\
0.62 & 1.3 & 1.8 \\
0.72 & 1.5 & 2.5 \\
0.82 & 1.7 & 3.4 \\
0.92 & 1.88 & 4.2 \\
1 & 2 & 5 \\
\hline
\end{tabular}

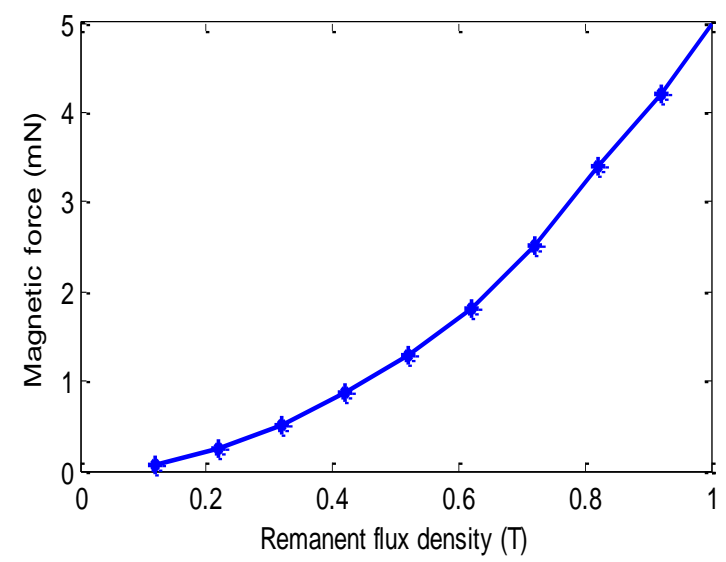

Fig.4. Magnetic Force as Function the Remanent Flux Density of Permanent Magnet

The repulsive magnetic force increase as function of variation of remanent flux density of permanent magnet, because the magnet generate the very important magnetic field and the magnetic interaction between particles and separator will be translate by very greater repulsive Lorentz force (Figure 4).

\subsection{Deflection distance of gold particle}

We can compute the different deflection distance of small gold particles as function of the gradient field of the magnets intensity or as function of magnetic force exerted upon the particles (figure 5). The results show the very important deflection of particle when gradient of magnet is elevated. 


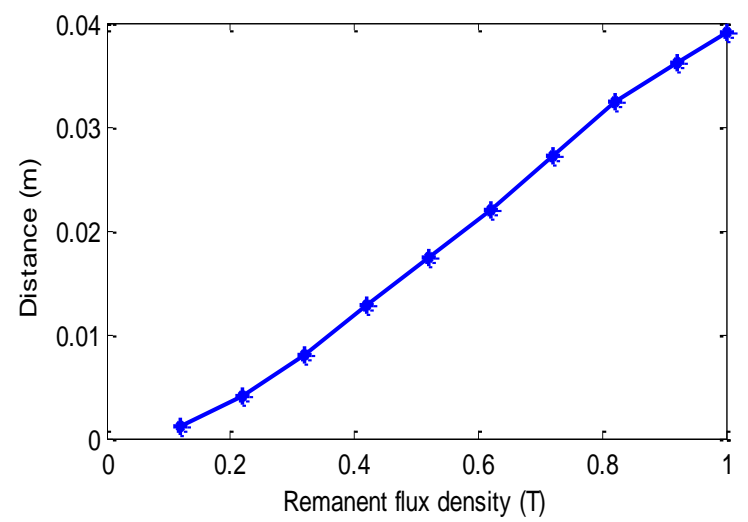

Fig.5. Deflection Distance of Gold Particle as Function the Gradient Field of the Magnets

\subsection{Variation of air gap of separator}

Variation of distance between the separator (permanent magnet) and particle for computation of induced eddy current and repulsive magnetic force upon particle of gold $(\mathrm{Au})$ with size $\mathrm{D}=1 \mathrm{Cm}$ (table 2).

Table 2. Variation of Air Gap Between Permanent Magnet and Particle.

\begin{tabular}{ccc}
\hline Air gap Y $[\mathrm{m}]$ & Induced eddy current $\left(\mathrm{A} / \mathrm{mm}^{2}\right)$ & Magnetic force $(\mathrm{mN})$ \\
\hline 0.005 & 2 & 4.5 \\
0.01 & 1.6 & 3 \\
0.02 & 1.3 & 2.1 \\
0.03 & 1.1 & 1.45 \\
0.04 & 0.95 & 1.05 \\
0.05 & 0.8 & 0.7 \\
0.06 & 0.7 & 0.5 \\
0.07 & 0.6 & 0.37 \\
0.08 & 0.52 & 0.26 \\
0.09 & 0.5 & 0.19 \\
0.1 & 0.42 & 0.13 \\
\hline
\end{tabular}

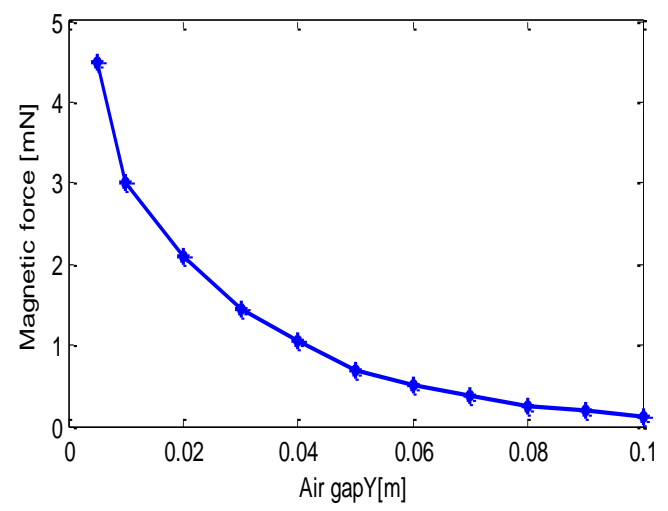

Fig.6. Magnetic Force as Function the Air Gap 
From Table2 the magnetic force depends to magnetic field intensity, when the particle is far the separator the air gap will be big and the magnetic force decrease, contrary when the air gap is small the repulsive force will be important (fig 6).

\subsection{Computation of ejection distance}

The repulsion distance of gold particles from sands depend of many parameters intensity of field size of particles ... the air gap between particles and magnet of separator play a great role in the process of eddy current separation because the magnetic wavelength of the separator and magnetic force, deflection distance decreases as function of air gap length (Figure 7).

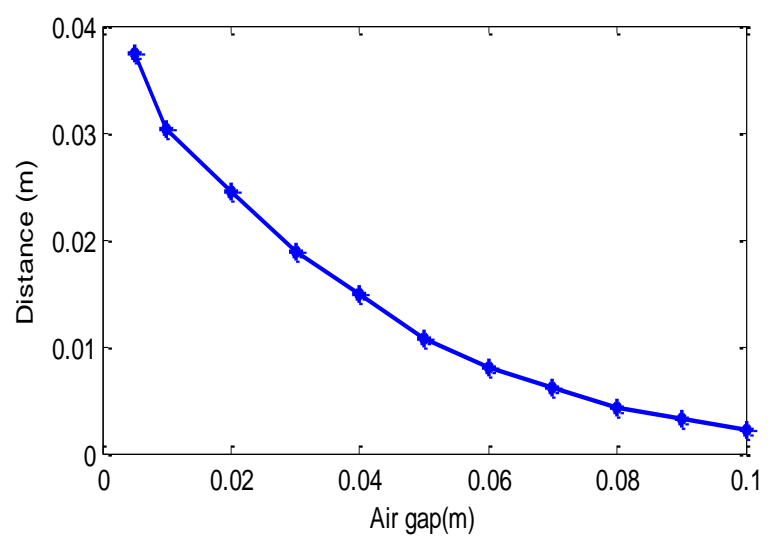

Fig.7. Deflection Distance of Gold Particle as Function the Air Gap

\section{Conclusion}

In this study we are simulate the characteristics of eddy current separator by finite element method already realized by many experimentally works and induced eddy current in small gold particle near the separator recovered from the feed material (sands).

The aim of this paper is to show influence of gradient field of permanent magnet and the air gap of drum upon magnetic force deflection and deflection distance.

The modelling and simulation of the interaction between the magnetic field and conductive particles is complicated characteristics of the particle (kind, size) the pole width or magnetic wavelength (air gap, gradient magnetic of permanent magnet) of the separator and deflection distance and by many others parameters will be studied in future works.

\section{References}

[1] P. C. Rem, E. M. Beunder, and A. J. van den Akker. 1998. Simulation of Eddy-Current Separators. IEEE transactions on magnetics, vol. 34, no. 4.

[2] Shunli Zhang a, Eric Forssberg a, Bo Arvidson b, William Moss 1998. Aluminum recovery from electronic scrap by High-Force eddy-current. Conservation and Recycling 23-225-241.

[3] Huifen Zhang1, a, Luzheng Chen2. 2014. Eddy-current induced magnetic separation of nonferrous metals from solid wastes. University of Science and Technology, Kunming 650093, China. 
[4] Jujun Ruan, Zhenming Xu. 2011. A new model of repulsive force in eddy current separation for recovering waste toner cartridges"' Journal of Hazardous Materials 192 (2011) 307-313.

[5] Popovic, Branko D. Introductory Engineering Electromagnetics", Addison-Wesley, Reading, MA1971.

[6] R. Ko“hnlechner a, Z. Schlett b, M. Lungu b, C. Caizer b. A new wet Eddy-current separator 2002. Resources, Conservation and Recycling 37 (2002) 55_/60 www.elsevier.com/locate/resconrec.

[7] R. Meier-Staude a, Z. Schlett b, M. Lungu b, D. Baltateanu. A new possibility in Eddy-Current separation"' Minerals Engineering 15 (2002) 287-291.

[8] Engineering company a division of arrowhead inductrial corporation 'Gold field magnetic separator'"55 south geneva road lindon Utah 84042 www.goldfielddeng.com.

[9] Z. Schlett, F. Claici, I. Mihalca, M. Lungu. A new static separator for metallic particles from metal-plastic mixtures, using eddy currents. Minerals Engineering 15 (2002) 111-113.

[10] Fabiano M, P Bevilacqua, Peter Rem. Modelling the throw of metals and nonmetals in eddy current separations Int. J. Miner. Process. 73 (2004) $1-11$.

[11] Mihai L. Separation of small nonferrous particles using an angular rotary drum eddy-current separator with permanent magnets Int. J. Miner. Process. 78 (2005) 22-30.

[12] Shunli Z, Eric F, B Arvidson, William Moss. Separation mechanisms and criteria of a rotating eddycurrent separator operation Resources, Conservation and Recycling 25(1999)215-232.

[13] J. Svoboda, T. Fujita. Recent developments in magnetic methods of material separation Minerals Engineering 16 (2003) 785-792.

[14] Shunli Z, Peter C. R, Eric Forssberg. Particle trajectory simulation of two-drum eddy current separators Resources, Conservation and Recycling 26 (1999) 71-90.

[15] Jujun R, Zhenming X. Environmental friendly automated line for recovering the cabinet of waste refrigerator Waste Management 31 (2011) 2319-2326.

\section{Authors' Profiles}

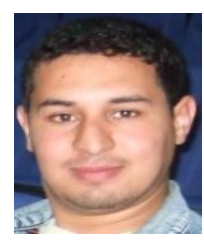

Ayad Ahmed Nour El Islam, was born in Algeria 1985. He received his master degree in electromagnetic compatibility from Djillali Liabbes University, Algeria in 2011. Currently, he prepares his Ph.D in electrical Engineering in Djillali Liabbes University. His major fields of interest are eddy current separator process.

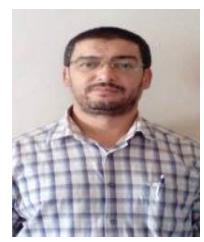

Ayad Abdelghani was born in Algeria in 1969. He received Ph.D. degree at the Sidi Bel Abbes University in 2009 in Electrical Engineering specializing in electromagnetic and CND control by eddy current. He is currently working at Sidi Bel Abbes University, Department of Electrical Engineering as an associate professor. The research interest is particularly about characterisation of materials by eddy current.

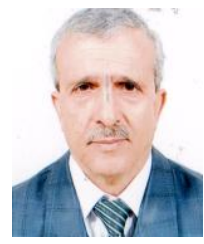

Ramdani Youcef was born in Sidi-Bel-Abbes, Algeria in 1952. He received the dipl.eng. Degree in electrical engineering from the university of science and technology, Oran, Algeria, in 1972, and the phd.degree from the university of Bordeaux, France, in 1989. He has been the director of the interaction réseaux electrique convertisseurs machines laboratory, university djilali liabes of sidi-bel-abbes, where he was also the head of the department of electrical engineering. His current research interests include electrostatics and high-frequency electronics. 